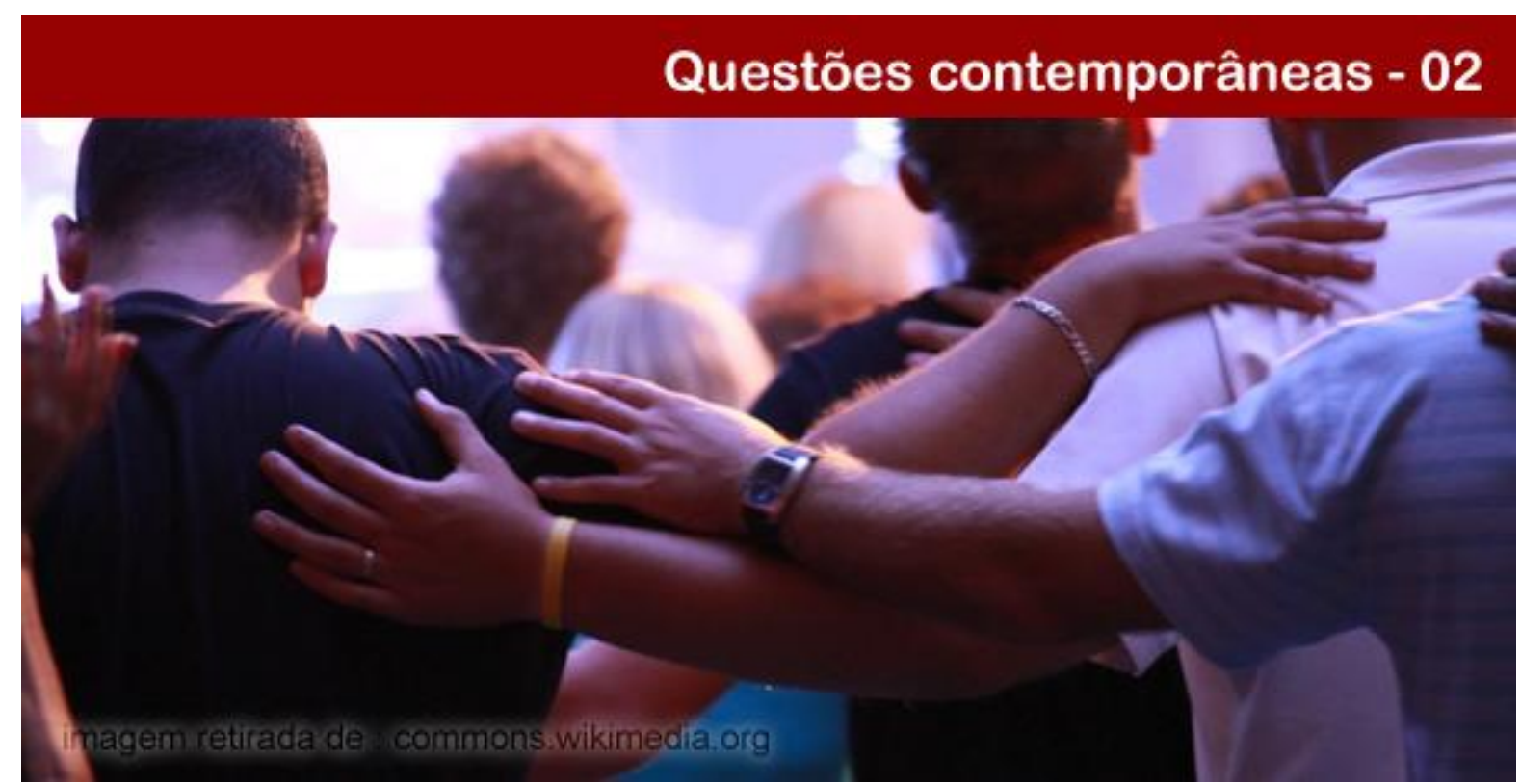

\title{
A RELIGIOSIDADE COMO ALTERNATIVA TERAPÊUTICA: UMA DISCUSSÃO DE GÊNERO SOBRE O SOFRIMENTO MASCULINO NA BUSCA PELA CURA
}

Pablo Luiz Santos Couto

Docente no Centro Universitário UNIFG. Enfermeiro. Mestre em Enfermagem pela Universidade Federal da Bahia (UFBA) na Linha Gênero, Mulher e Saúde. E-mail: pablocouto0710@gmail.com.

\section{Elionara Teixeira Boa Sorte}

Docente na Universidade do Estado da Bahia (UNEB). Enfermeira. Mestra em Enfermagem pela Universidade Federal da Bahia (UFBA) na Linha Gênero, Mulher e Saúde. E-mail: natatbsorte@gmail.com.

\section{Sandra Célia Coelho Gomes da Silva}

Docente na Universidade do Estado da Bahia (UNEB). Socióloga. Doutora em Ciências da Religião pela Pontifícia Universidade Católica de Goiás.E-mail: sandraccgs@hotmail.com.

Resumo: O fenômeno religioso tem sido objeto de estudo socioantropológico, sendo articulado com as teorias de gênero e da sexualidade, para explicar as construções sociais fomentadas pela religião. Os objetivos principais deste artigo foram refletir sobre o sofrimento do homem, na busca pelo milagre de cura e (re)discutir o papel e o comportamento masculino, socialmente construídos, a serem desempenhados na religião. Trata-se de um estudo descritivo, com abordagem qualitativa. As técnicas de coleta de dados utilizadas foram: observação participante e a entrevista semiestruturada. $\mathrm{O}$ universo de pesquisa foi uma Igreja Evangélica e os participantes foram 23 homens, membros da igreja, que afirmaram ter obtido a cura milagrosa. Fica posto que, em meio às relações de poder estabelecidas na igreja e no lar entre homens e mulheres, os homens mostram o seu lado sensível ao se voltar para o sobrenatural na obtenção da cura milagrosa, desconstruindo parte do que é defendido socialmente como sentimento masculino.

Palavras-chave: Antropologia. Religião. Religiosidade. Gênero.

\section{RELIGIOSITY AS AN ALTERNATIVE THERAPY: A DISCUSSION OVER MALES SUFFERING IN THE SEARCH FOR A CURE}

Abstract: The religious phenomenon has been the subject of socio-anthropological study, combined with the theories of gender and sexuality to explain social constructions fostered by religion. The main objectives of this

\section{POLÊM!CA | LABORE (}

Polêmica - Revista Eletrônica da Uerj - Rua São Francisco Xavier, 524, $1^{\circ}$ andar bloco D, sl.1001 • Tels.: +55 21 2334-4088 / 4087 • http://www.e-publicacoes.uerj.br/index.php/polemica/index http://www.labore.uerj.br • laboreuerj@yahoo.com.br 
paper were to reflect on human suffering in the search for the miracle of healing and discuss the role and male behavior socially constructed to play in religion. This is a descriptive study and socio-anthropological, with a qualitative approach. The data collection techniques used were participant observation and semi-structured interview. The universe of research was an evangelical church and participants were 23 men, church members, who claimed to have obtained the miracle cure. It is given that, amid the power relations established in the church and in the home for men and women, men show their sensitive side to turn to the supernatural in obtaining the miracle cure, deconstructing part of what is socially defended as male feeling.

Keywords: Anthropology. Religion. Religiosity. Gender.

\section{Introdução}

Ao longo história humana, estudos antropológicos têm notado que a religiosidade tornou-se algo inerente ao ser humano, fomentado pelo misticismo, simbolismo e magia das práticas religiosas, o que tem levado alguns pesquisadores (PARKER, 1995; ROSADONUNES, 2005; ROCHA, 2008) a questionarem o verdadeiro sentido da religião, que funciona como um dispositivo de poder, que desperta sentimentos de perseverança e esperança através da fé, a ponto de receberem das divindades a resposta para as suas necessidades, principalmente, a cura de doenças (PARKER, 1995).

Os estudos das religiões ou do fenômeno religioso, em seus diferentes enfoques teóricos, têm exigido uma visão interdisciplinar que procure romper com a superficialidade teórica e contribua para a compreensão do cotidiano das pessoas. O grande desafio nesse campo, na contemporaneidade, é compreender o fenômeno religioso como fundamental para entender a diversidade cultural.

Durkheim afirmava que quase todos os aspectos da vida são permeados pela religião. Os cerimoniais religiosos tanto originam novas ideias e categorias de pensamento, quanto reafirmam os valores existentes (DURKHEIM, 1989; GIDDENS, 2005). Na religião, há um dispositivo ideológico em que ocorre uma transmissão prática e simbólica da perpetuação da memória de um acontecimento a partir de uma 'linhagem religiosa' (HERVIEU-LÉGER, 2008).

Na verdade, se observa que algumas pessoas só preenchem o vazio de sua alma quando desenvolvem a sua espiritualidade, passando a crer em algo ou alguém que lhes dê direção ou mostre um caminho a partir de símbolos e rituais que os levem a ter as suas necessidades atendidas (DURKHEIM, 1989; LEMOS, 2010).

As religiões envolvem um conjunto de símbolos, que invocam sentimentos de reverência ou de temor, e estão ligadas a rituais ou cerimoniais (como os serviços religiosos,

\section{POLÊM!CA $\mid$ LABORE}

Polêmica - Revista Eletrônica da Uerj - Rua São Francisco Xavier, 524, $1^{\circ}$ andar

bloco D, sl.1001 • Tels.: +55 21 2334-4088 / 4087 • http://www.e-publicacoes.uerj.br/index.php/polemica/index

http://www.labore.uerj.br • laboreuerj@yahoo.com.br 
tais como orações de libertação e cura, imposição de mãos) dos quais uma comunidade de fiéis participa (GIDDENS, 2005, p. 427).

Parker (1995) afirma que os indivíduos, principalmente os marginalizados, buscam satisfazer de forma mais imediata seus desejos e anseios, uma vez que, pela situação de miséria, sofrem privações, tornando compreensível o vínculo com experiências religiosas que suprem algumas necessidades vitais. Giddens (2005) segue concordando com esse pensamento quando diz que "as pessoas, muitas vezes, recorrem à magia em situações adversas ou em caso de perigo" (p. 427).

$\mathrm{Na}$ tarefa de reconstruir um tecido social prejudicado por questões sociais (pobreza, analfabetismo, agravos à saúde, dentre outros), ou seja, pelas situações de miséria supracitadas, foram surgindo novas práticas e novos valores e uma nova perspectiva foi se afirmando. Assim, a sociedade tem procurado resgatar velhas facetas da cultura e da religião das classes populares, com a invocação do divino através do misticismo cristão, tais como os rituais como campanhas de oração e cultos de cura (PARKER, 1995, p. 39).

No mundo atual, percebe-se que o ritual de cura encontrado nas inúmeras religiões encaminha o ser humano em busca do sagrado, a relacionar-se por meio da fé com alguma divindade que tenha o poder de solucionar seus problemas de forma imediata, como é caracterizado no perfil imediatista das pessoas ao longo dos séculos e do desenvolvimento da sociedade e civilizações (HERVIEU-LÉGER, 2008; LEMOS, 2010). Esse relacionamento do homem com a sua divindade só é compreendido a partir do ritual e/ou simbolismo realizado, pois é a partir dele que a cura é alcançada. Assim, o entendimento dos rituais nas curas sobrenaturais ocorre quando o ser humano se liga e conecta-se com o cosmos e alcança os poderes atribuídos à divindade mediante à prática dos rituais (NEVES, 1984).

Na Babilônia, a população invocava o Deus Marduc para libertá-la das situações negativas que assolavam sua vida, em que a possessão demoníaca da qual sofria estava ligada ao estado no qual se encontrava e, por sua vez, implicava na doença. O próprio cristianismo herdou de culturas antigas, como as mesopotâmicas e a egípcia, a crença de que em muitos casos as doenças eram causadas pelos demônios, pelos monstros ou espíritos ruins e que, portanto, deveria recorrer aos deuses por meios mágicos para se obter a cura (LEMOS, 2011).

Tal idéia tem se perpetuado há séculos, principalmente nas religiões derivadas do cristianismo, em especial, as igrejas evangélicas onde há uma batalha desenfreada contra o que

\section{POLÊM!CA $\mid$ LABORE}


consideram as assolações impostas pelos demônios/diabo, como as doenças. Desse modo, muitos recorrem à prática religiosa, pois têm a fé que 'Deus irá intervir e derrotar o inimigo' (diabo/demônios/satanás) causador das moléstias.

Para Lévi-Strauss (1970), não se deve duvidar que as práticas mágicas têm sua eficácia, já que a crença está ligada à magia. Ele ainda diz que a crença é observada dos dois lados: por parte do enfermo (fiel) e por parte de quem realiza o ritual (santo/pastor/feiticeiro).

Nas igrejas e nos encontros em que a cura será ministrada, as pessoas são bem recebidas com sentimentos calorosos por parte de todos ali presentes, já que pelo menos ali terão a certeza de que serão tratados como deve ser - respeitados - e não como seres renegados pela sociedade e jogados na sarjeta. Santos, Koller e Pereira (2004) destacam que nas igrejas o doente é tratado como um fiel - um irmão em Deus - em um ambiente predominado pela compaixão e pela ajuda mútua, e não como um objeto que a medicina oficial costuma tratar o doente.

A religiosidade é vivenciada de modo diferente pelo homem e pela mulher. Enquanto eles são minoria, porém responsáveis por impor regras, normas, doutrinas bem definidas na maioria das religiões; elas, que formam a maioria, são responsáveis por manter e seguir o que é imposto pelos homens, bem como pelo investimento na prática religiosa, nos rituais, na transmissão dos conhecimentos (ROSADO-NUNES, 2005; ROCHA, 2008).

No contexto cultural e religioso onde é invocado o ser homem ou mulher, a sociologia tem se dedicado à análise da prática religiosa no que diz respeito ao gênero, uma vez que é possível identificar nas entrelinhas a clareza da construção social dos papéis desempenhados por mulheres e homens, na configuração e vivência no meio das religiões (ROCHA, 2008).

É perceptível entre os dados estatísticos a confirmação de que no senso comum

[...] as mulheres investem mais em religião do que os homens. Daí se conclui que elas seriam mais religiosas que eles. Tal visão esconde um enorme equívoco que as atuais formas fundamentalistas das religiões, no Ocidente como no Oriente, vêm desvendar. $\mathrm{Na}$ verdade as religiões são um campo de investimento masculino por excelência (ROSADO-NUNES, 2005, p. 363).

Diante do que foi exposto, observa-se que a religiosidade leva o indivíduo a buscar de alguma forma um contato com uma divindade, esperando que elas lhes propiciem respostas às suas preces, caracterizando, portanto, uma espécie de troca para a obtenção da cura.

\section{POLÊM!CA $\mid$ LABORE}




\section{Gênero e religião: entendendo o lugar do homem nas práticas religiosas}

Para que a relação entre gênero e religião seja compreendida, é importante conceituar o primeiro termo. Segundo Carvalho (2007), o termo "gênero" designa os comportamentos e atitudes que a sociedade atribui a homens e mulheres, o que é ideologicamente fundamentado e justificado na diferença sexual.

Na verdade, o jeito de ser masculino ou feminino é bem variável e mutável, o que faz assumir uma forma hegemônica dentro de um determinado grupo e contexto social, ou seja, a construção da identidade do ser humano, depende de inúmeros fatores como o social, cultural, fisiológico, étnico, dentre outros, implicando na construção social do masculino e feminino.

Essas construções sociais que norteiam as relações de gênero são fortalecidas pelo conceito formulado por Joan $\operatorname{Scott}^{1}$, quando afirmou que gênero se constitui a partir de relações sociais fundamentadas nas diferenças percebidas entre os sexos que, por sua vez, ocorrem dentro das relações de poder cujos usos e significados emanam de uma disputa política e é como as relações de poder - de dominação e de subordinação - se constroem (SCOTT, 1995).

O termo "gênero" tem aproximadamente um século de uso, aparecendo, porém como categoria e conceito nas ciências sociais na década de 70. A relação de gênero com a história data com o surgimento do feminismo e luta das mulheres pela igualdade de direitos e as discussões a respeito do modo ser feminino (mulher) ou masculino (homem) (ROCHA, 2008).

Essa afirmação é corroborada por Bellotti (2007). Segundo ele, com o

[...] desenvolvimento do capitalismo e do cientificismo na Europa, a partir do século XVII em diante, o determinismo biológico ajudou a reforçar a divisão das esferas pública e privada, dóceis e domesticadas para o lar e para o matrimônio; homens na esfera pública, cuidando da administração, da política e da economia (p. 167).

Desse modo, os estudos sobre gênero voltaram o olhar para as diferenças dos papéis e do atributo do ser humano na sociedade em uma relação com pessoas pertencentes a categorias distintas que se manifestam, sentem e atuam de acordo o sexo por meio de construções socioculturais, nas maneiras de agir cotidianas.

Ao explicitar a diferença de gênero, Lamas (2000) aborda o feminismo dizendo que a sua eficácia está na abordagem do conflito entre homem e mulher e nas relações de poder entre

\footnotetext{
${ }^{1}$ Joan Scott, feminista norte-americana, é professora da Escola de ciências Sociais do Instituto de altos Estudos de Princeton, Nova Jersey. É especialista na história do movimento operário no século XIX e do feminismo na França. É uma das teóricas mais importantes no estudo da categoria gênero (SCOTT, 1995).
}

\section{POLÊM!CA $\mid$ LABORE}


essas pessoas; o conflito surge no momento que um bebê é concebido. Nesse momento, introjeta-se na futura criança um simbolismo cultural do que é ser masculino e feminino.

Dentro das religiões cristãs, em especial as ditas evangélicas, as observações pontuadas acima são muito presentes em instituições religiosas e em outras áreas da vida do(a) fiel, onde geralmente as mulheres são excluídas do poder, sendo um tema decididamente masculino, tanto no simbolismo como na hierarquia. Nos textos bíblicos, por exemplo, os papéis principais em sua maior parte são destinados aos homens (GIDDENS, 2005).

Destarte, apresentamos como os objetivos deste artigo: (re)discutir o papel e o comportamento masculino construídos socialmente a ser desempenhado na religião e refletir sobre o sofrimento do homem na busca pelo milagre de cura, a partir da fala de Carvalho (2007) quando afirmou que "céu e guerra são um espaço de atividade masculino [...] e estes (homens) não podem chorar as misérias e sofrimento do mundo" (p. 28).

\section{Metodologia}

O fenômeno religioso há algum tempo vem sendo objeto de estudo e pesquisa, nas mais variadas partes do mundo e dentro de contextos sociais diversificados. Segundo Lemos (2011), a tentativa de alguns autores em conceituar religião evidencia a dificuldade de apresentá-la de forma isolada de suas concepções mais gerais da sociedade. Portanto, a religião pode ser definida como aquela depositária de significados culturais pelos quais indivíduos e coletividades são capazes de interpretar a própria condição de vida, construir para si uma identidade e dominar o próprio ambiente (LEMOS, 2010).

Este é um estudo socioantropológico, descritivo, na perspectiva de uma pesquisa de campo, cuja abordagem adotada foi qualitativa. Trata-se de um recorte dentro de um projeto 'guarda-chuva', desenvolvido pelo Grupo de Estudos e Pesquisas em Educação, Religião, Cultura e Saúde ${ }^{2}$, intitulado A espiritualidade como alternativa terapêutica. Como técnicas de coleta de dados foram adotadas a observação participante e a entrevista semiestruturada, nas quais os instrumentos utilizados foram o diário de campo e o roteiro para entrevista semiestruturada, aplicados em duas etapas.

\footnotetext{
${ }^{2}$ Grupo de Estudos e Pesquisas em Educação, Religião, Cultura e Saúde (GEPERCS): Grupo Interdisciplinar e interinstitucional, sediado na Universidade do Estado da Bahia e vinculado ao Centro de Estudo Interdepartamental em Ciência da Religião, coordenado pelo Professor Adjunto Paulo Cézar Borges Martins.
}

\section{POLÊM!CA $\mid$ LABORE}


O universo de estudo foi a Igreja Evangélica Batista Filadélfia Independente (IBFI) de Guanambi - Bahia (BA) e os participantes da pesquisa foram os fiéis do sexo masculino. Adotou-se como critérios de inclusão: apenas homens maiores de 18 anos que se consideravam curados de uma doença por meio do sobrenatural divino, ou seja, o milagre. Foram entrevistados 23 homens que se dispuseram contribuir com a pesquisa após o convite feito em um dos cultos.

Na primeira etapa da pesquisa foram observados os costumes, os rituais, as simbologias, as ideologias e o cotidiano dos fiéis na igreja. Verificou-se, por meio do cadastro de membros, que a Igreja possui um total de aproximadamente 2000 membros, sendo cerca de 1100 frequentadores da sede. Tudo o que pode ser observado nos dois meses (março a abril de 2011) de coleta de dados foi anotado no diário de campo.

$\mathrm{Na}$ segunda fase, foi aplicado um roteiro de entrevista semiestruturada, que continha questões fechadas visando a caracterização dos homens e três perguntas abertas com a finalidade de saber a respeito do momento de dor (período da doença) e cura, a importância da religião para eles e os rituais mais praticados na obtenção da cura.

Todas as etapas dos aspectos éticos envolvendo as pesquisas com seres humanos foram respeitadas em consonância com os requisitos éticos determinados pela Resolução n 466/2012 do Conselho Nacional de Saúde (CNS). As entrevistas iniciaram após a aplicação do Termo de Consentimento Livre e Esclarecido.

\section{Resultados e discussão}

A sociedade é um produto humano, assim como o homem é um produto da sociedade. O homem não pode existir independente da sociedade, havendo um caráter inerentemente dialético do fenômeno social. A sociedade funciona como ação formativa da consciência individual, toda sociedade enfrenta o problema em transmitir os seus sentidos objetivados, de uma geração para a outra, que chamamos de cultura (LÉVI-STRAUSS, 1970; DURKHEIM, 1989; LEMOS, 2011).

Surge, então, a construção de uma identidade subjetiva, mediatizada por uma realidade objetiva. Essa identidade molda o indivíduo, não como um ser passivo, e sim dentro de uma realidade de mundo em que ele é participante, ou melhor, o mundo social mediatizado por uma

\section{POLÊM!CA LABORE}


linguagem própria. Isto é, o indivíduo continua a ser um coprodutor, do mundo social, e por isso, de si mesmo.

Para o grupo de homens que contribuíram com a pesquisa, a doença é analisada a partir de dois pontos de vista que emergiram das falas: primeiro, como "algo espiritual causado pelo diabo", já que "é o inimigo que manda uma enfermidade" devido "a brecha dada a ele", decorrente da vida de pecado, sem a busca pelo arrependimento com Deus; e, segundo, como uma “consequência biológica própria do ser humano", uma vez que esse "é pecador desde o nascimento".

Santos, Koller e Pereira (2004) afirmam que

[...] as causas das doenças, colocadas pela igreja, enquadram-se melhor na categoria de doença-punição, uma vez que estas são vistas como conseqüências provocadas pelo próprio indivíduo ou grupo. A doença seria a transgressão de uma lei. Dessa forma, a noção de reparação se torna possível a partir de um retorno a essas leis (p. 86-87).

Esses indivíduos acreditam que a cura ocorre segundo a vontade de Deus e suas promessas, contidas na Bíblia, por isso é tão importante para essas pessoas o conhecimento bíblico.

Em Thompson (2007), destacam-se alguns versículos no que tange à cura e que foram relatados pelos homens em suas falas:

- Exôdo, capítulo (cap.) 23 e versículo (ves.) 26, Deus afirma: - porque eu sou o Senhor que te sara;

- Mateus, cap. 8 e ves. 17 - Ele tomou sobre si as nossas enfermidades e levou as nossas doenças;

- Marcos, cap. 9 e ves. 23 - Tudo é possível ao que crê.

- Jeremias, cap. 1 e ves. 12, diz Deus: - Eu velo sobre minhas palavras para cumpri-las.

É baseado nos versículos acima e em muitos outros que os fiéis acreditam e têm fé que Deus irá curá-los das doenças, afinal, como disse um deles "não existe doença incurável para Deus, pois Ele os ama acima de tudo”.

Neves (1984) afirma que o doente da igreja muitas vezes é um pecador-crente, sendo esse um ser paradoxal castigado ou abandonado por Deus, mas com chances de reconciliar com Ele, devido a Graça e ao Amor Incondicional demonstrado por Deus, por meio de Jesus Cristo seu filho, morto na cruz e ressuscitado ao terceiro dia pela remissão dos pecados da humanidade.

\section{POLÊM!CA $\mid$ LABORE}


Na verdade, o que foi observado nos diálogos é que há o medo "das doenças graves $e$ perigosas", "de morrer antes do tempo, pois tenho que cuidar e guiar minha família" e a crença de que a doença, se não pode ser curada de forma imediata pela ciência médica, há a esperança de que Deus pode intervir e curar, pois como é dito no meio dos cristãos e da IBFI e sustentado por alguns dos homens "Deus é o Todo Poderoso. Ele pode todas as coisas" ou "Jesus morreu por mim, pelos meus pecados e doenças: Ele tem o poder de me curar”.

Lemos (2010) corrobora com a análise quando diz que

[...] dentro de sua concepção de uma vida com sentido, a saúde se apresenta como uma necessidade imprescindível, uma vez que o ser humano se compreende como um ser para a vida, e a doença aponta em direção à morte, portanto, em direção ao caos e ao sem sentido (p. 262). (A religião aponta para a fé no milagre, portanto, para a vida.).

Dentre os rituais que levam esses homens a clamar pelas suas curas, os mais relatados e observados foram: as campanhas de oração (30\%), em que um grupo de irmãos se reúne no templo ou nas casas durante três ou sete semanas (um dia da semana) seguidas, ou então, três ou sete dias seguidos; as vigílias de oração (11\%) em que os irmãos se reúnem no templo, geralmente, das 21:00 horas às 07:00 horas da manhã seguinte, sempre com pedidos dos mais variados, principalmente de cura; e por fim, uma oração simples (59\%), declarando as palavras da Bíblia e as promessas de Deus, essa foi a mais relatada pelos fiéis.

Esse último ritual como o mais praticado - bem como os dois primeiros - servem para comprovar a observação de que os cristãos da IBFI creem e se apegam à Bíblia e às promessas contidas nela. Para esses indivíduos “a Bíblia é a palavra de Deus e ponto final”. A religião os ensina a manusear a Bíblia que, por sua vez, desperta neles a fé em Deus através da Graça dada por Jesus Cristo, e para eles dá no mesmo crer nos dois (Deus e Jesus Cristo), "por que ambos têm o mesmo poder, são pai e filho e estão lado a lado no céu”, disse um dos entrevistados.

"O fenômeno religioso aparece no campo das significações e linguagens de uma coletividade quando esta se vê frente com o problema limite, ou seja, quando a população se defronta com a grande contradição vital: garantir a reprodução da vida nesta terra e além dela" (PARKER, 1995, p. 50-51).

A doença tende a aproximar a morte - o fim - do homem, mas os rituais religiosos praticados para a obtenção da cura dão a esperança de viver e o aproximam da divindade em que acreditam (Deus), por intermédio do poder associado ao nome de seu filho Jesus Cristo,

\section{POLÊM!CA $\mid$ LABORE}

Polêmica - Revista Eletrônica da Uerj - Rua São Francisco Xavier, 524, $1^{\circ}$ andar

bloco D, sl.1001 • Tels.: +55 21 2334-4088 / 4087 • http://www.e-publicacoes.uerj.br/index.php/polemica/index

http://www.labore.uerj.br • laboreuerj@yahoo.com.br 
aquele que concede o milagre. Desse modo, o homem experimenta a transcendência e percebe o sentido da vida. Lemos (2011) considera que o sofrimento é um desafio para a religião, pois através dela, com a intenção de buscar milagres para moléstias e sofrimentos, o ser humano obtém fuga da realidade terrena para o divino sobrenatural. As doutrinas cristãs que tratam de rituais de cura e de milagre, presentes na Bíblia, são defendidas pelas religiões evangélicas e têm suas raízes na cultura judaica, em que os sacerdotes intermediavam a cura junto a Deus. Cura que se dava por práticas consideradas sobrenaturais, assim como é visto entre aqueles que buscam a saúde por meio do milagre dentro do templo da IBFI (OLIVEIRA, 2005).

Dos vinte e três entrevistados, dezesseis (70\%) eram casados e possuíam filhos, cinco $(26 \%)$ eram apenas casados e dois $(04 \%)$ eram solteiros. Foi comum observar nas falas dos depoentes a posição como a autoridade maior na família, portanto chefes de família, responsáveis pelo bem-estar e segurança dos seus entes; inclusive, entre os solteiros também foi perceptível essa postura, já que fora herdada pelo meio social e da criação a qual foram submetidos, logo, construído socialmente, no cotidiano familiar e da igreja. Isso pode ser evidenciado na fala de um dos homens jovens participantes: “ [...] estou noivo e ano que vem casarei e estarei constituindo minha família e, como somos muito tementes aos ensinamentos de Deus, temos consciência, eu e minha noiva, de que eu serei tudo para ela e que será eu quem conduzirá nossa família nos caminhos do senhor".

Bourdieu (1999) explica que nos aspectos da vida social há um sistema de dominação masculina, institucionalizado e internalizado, os quais se expressam na cultura, na ideologia, ciência, violência, sexualidade, reprodução (...). Assim, as relações de classe, raça e gênero são relações de poder que têm como parâmetro universal os princípios masculinos. Veem-se aí famílias predominantemente patriarcais, que identificam o homem como a identidade moral, que conferem a esses indivíduos um sentimento de orgulho pessoal, pois dominam os seus e, principalmente, as mulheres, econômica, sexual e culturalmente, no âmbito privado, onde se estabelecem as relações de poder.

É importante salientar que as esposas trabalham fora de casa, como foi destacado na fala de um dos entrevistados: "essencial no mundo atual, uma vez que não dou conta de sustentar a casa sozinho, pois o salário é pouco e as despesas são muitas, mesmo assim eu continuo sendo o cabeça do lar, como está na Bíblia, que o homem é o líder da casa”. Outro também disse: "Não é porque a mulher trabalha fora, que ela não deva respeitar o marido e, aceitar

\section{POLÊM!CA | LABORÉ}


que o homem foi instituído por Deus como o cabeça da família”, além disso, foi perceptível na observação participante que tal fato é defendido pelos membros da igreja e reverberado pelas mulheres.

A religião, através do(a)s fiéis, sustenta o discurso patriarcal e machista, ao defender a posição do homem como chefe e responsável do lar e atribuindo à mulher e aos filhos o dever de serem submissos. Na igreja observada, os homens refletem esses discursos ao desempenharem a liderança de diversos grupos e departamentos, sendo poucas as mulheres que lideram algum grupo ou têm um cargo administrativo importante (a exceção fica pelo grupo de mulheres e senhoras).

Quanto a essa postura masculina do homem evangélico, Sarti (1994) afirma o seguinte:

A identificação do homem como autoridade moral, a que confere respeitabilidade à família, não se altera. (...) Não é, portanto, necessariamente o controle dos recursos internos do grupo doméstico que fundamenta a autoridade do homem, mas sim seu papel de intermediário entre a família e o mundo externo, em seu papel de guardião da respeitabilidade familiar (p. 47).

No que diz respeito à participação nas práticas rituais e simbolismos religiosos, foi dito no início que as mulheres têm maior envolvimento, no entanto, dentro da IBFI de Guanambi BA, ambos os sexos estão envolvidos. Mais ainda, os homens também praticam os ritos que os levam a buscar a intervenção divina, uma vez que 70\% dos entrevistados desenvolvem alguma atividade/função na igreja, de diáconos, obreiros ou líderes de algum outro ministério.

Os indivíduos entrevistados foram unânimes em afirmar que a religião deles é de fundamental importância nos momentos de necessidade, pois ela os leva a confiar nas promessas de Deus, que consequentemente aponta para a fé e a crença de que "tudo é possível através das orações feitas ao Senhor" e que a oração, seja ela realizada a partir de qualquer ritual permitido pela igreja "tem poder e unção, já que [o milagre] é a resposta de Deus às necessidades através da oração do fiel".

Fica posto que, em meio às relações de poder estabelecidas na igreja e no lar entre homens e mulheres, os homens se voltam para o sobrenatural na obtenção da cura milagrosa, desconstruindo parte do que é defendido socialmente como sentimento masculino. Entretanto, através das observações e das entrevistas, foi reforçado que o machismo e o patriarcalismo imperam na igreja pesquisada, defendido, inclusive pelas mulheres evangélicas.

\section{POLÊM!CA LABORE}




\section{Considerações finais}

Foi possível refletir, por meio do objeto investigado, que algumas religiões, como a evangélica, desempenharam e continuam desempenhando uma função estratégica no empreendimento humano, na construção do mundo e na sua manutenção. Isto ficou claro em relação aos homens da IBFI participantes deste estudo. Ela representa o ponto máximo de autoexteriorização dos sujeitos investigados dos seus próprios sentidos sobre a realidade, levandoos a manter a ordem subjetiva de seus corpos através da busca do milagre e da cura.

Embora algumas doutrinas religiosas tenham uma tendência intrínseca para legitimar a alienação (PARKER,1995; LEMOS, 2011), há também uma possibilidade contrária, ou seja, a de que a desalienação passe a ser legitimada através delas (religiões), as quais aparecem no contexto histórico como uma força que sustenta e embala o mundo. Em todas as suas manifestações ela serve para instituir significados na amplidão do universo vazio de cada pessoa. Com isso, é importante reiterar que as igrejas, independente da linha doutrinária, mantém uma função social que contribui para as construções sociais dos papéis desempenhados por homens e mulheres em seus cotidianos e, consequentemente, nas relações de poder no privado (lar) e no público (na igreja).

As crenças religiosas têm se especializado em auxiliar na fé dos fiéis a partir do estímulo da religiosidade por meio de práticas que envolvem os rituais, as doutrinas e os simbolismos. Isso tem levado muitas pessoas a procurar, cada vez mais, a satisfação das necessidades por meio do sobrenatural, já que as religiões suprem aquilo que o sistema não oferece.

Estas ponderações foram percebidas a partir das observações feitas na Igreja Evangélica e evidenciadas nas falas dos homens que participaram da pesquisa, os quais frisavam que estão firmados no poder de Deus, através do seu Filho Jesus Cristo, mediante os rituais nela identificados, e que, por isso, tiveram suas preces de cura atendidas.

No caso dos rituais praticados na IBFI, estes visam remover as penúrias dos membros por meios dos simbolismos, principalmente, a cura através da intervenção divina. O que fica mais evidente é que os ritos são voltados à oração em concordância com a Bíblia, considerada pelos homens e membros da igreja como a Palavra de Deus, uma vez que eles são influenciados a ler para conhecer as promessas de cura.

É importante salientar que o perfil desses homens, que buscam a restauração da saúde por intermédio do cosmos e do sobrenatural, já foi bastante discutido por outros autores

\section{POLÊM!CA $\mid$ LABORE}


(PARKER, 1995; BELLOTI, 2007; ROCHA, 2008; LEMOS, 2010, 2011), porém, conforme os resultados deste presente estudo com homem evangélicos da IBF, apesar de serem autoridades em suas famílias, mostram-se sensíveis e humanos, diferente do que se espera de uma atitude típica masculina (homens que não podem chorar e serem sensíveis).

O orgulho desses homens é se apresentar à sociedade como líderes e guardiões do seu lar e, portanto, patriarcas em suas famílias, num contexto religioso e social. Sendo assim, como o objetivo dessa discussão foi mostrar que, dentro das denominações religiosas, a visão machista e a figura do homem como ser dominante ainda impera, tem-se posto uma contraditoriedade entre o que é determinado e aceito socialmente como sentimentos esperados para o sexo masculino: os homens que frequentam a IBFI, ainda que sejam dominantes e machistas, tem no templo um lugar onde é permitido que expressem e revelem suas vulnerabilidades diante de Deus, tendo os demais membros como testemunha.

\section{Referências}

BELLOTI, Karina Kosicki. Gênero e religião. In: do Campo: Umesp, 2007.

. Gênero e Religião: Ensaios feministas. São Bernardo

BERGER, Peter. Religião e Construção do mundo. In: BENEDETTI, Luiz Roberto. O dossel Sagrado:

Elementos para uma teoria sociológica da religião. Trad. José Carlos Barcelos. São Paulo: Paulinas, 1985. p. 15113.

BOURDIEU, Pierre. Gênese e Estrutura do campo religioso. In: A economia das trocas simbólicas. 5. ed. São Paulo: Perspectiva, 1998.

A dominação masculina. Rio de Janeiro: Bertrand Brasil, 1999.

CARVALHO, Maria Eulina Pessoa de. Uma agenda de pesquisa, formação humana e docente em gênero e educação. In: Maceió: Edufal, 2007.

DURKHEIM, Émile. As formas elementares da vida religiosa. Trad. Joaquim Pereira Neto. São Paulo: Paulinas, 1989.

GIDDENS, Anthony. Sociologia. Trad. Sandra Regina Netz. 4. ed. Porto Alegre: Artmed, 2005.

HERVIEU-LÉGER, Daniéle. O peregrino e o convertido - a religião em movimento. Petrópolis: Vozes, 2008.

LAMAS, Marta. Gênero: os conflitos e desafios do novo paradigma. Rev. Proposta, Rio de Janeiro, v. 84, n. 85, p. 12-25, mar/ago. 2000 .

LEMOS, Carolina Teles. Catolicismo, sexualidade e AIDS: pertencer sem ser fiel. Soc. e Cult., Goiânia, v. 13, n. 2, p. 259-268, jul./dez. 2010.

\section{POLÊM!CA IABORE}

Polêmica - Revista Eletrônica da Uerj - Rua São Francisco Xavier, 524, $1^{\circ}$ andar

bloco D, sl.1001 • Tels.: +55 21 2334-4088 / 4087 • http://www.e-publicacoes.uerj.br/index.php/polemica/index

http://www.labore.uerj.br • laboreuerj@yahoo.com.br 
Vida e medo: concepções de corpo e sexualidade na tradição cristã-católica. Horizonte, Belo Horizonte, v. 9, n. 21, p. 284-305, abr./jun. 2011.

LÉVI-STRAUSS, Claude. Antropologia Estrutural. Rio de Janeiro: Tempo Brasileiro, 1970.

NEVES, Delma Pessanha. As Curas Milagrosas e a Idealização da Ordem Social. Niterói: UFF, 1984.

NOÉ, Sidnei Vilmar. (org.). Espiritualidade e Saúde: da cura d’almas ao cuidado integral. 2. ed. São Leopoldo: Sinodal, 2004.

OLIVEIRA, Paulo César Nunes de. Alguém me tocou. Eu senti que uma força saía de mim: Um ensaio sobre Jesus e os taumaturgos de seu tempo. In: . Corpo, Gênero, Sexualidade, Saúde. Goiânia: Ed. da UCG, 2005.

PAIVA, Geraldo José de. Religião, enfrentamento e cura: perspectivas psicológicas. Estud. psicol., Campinas, v. 24, n. 1, mar. 2007.

PARKER, Cristián. Religião Popular e modernização capitalista: outra Lógica na América Latina. Tradução de Attílio Brunnetta. Petropólis/RJ: Vozes, 1995.

ROCHA, Maria José Pereira. Gênero e religião sob a ótica da redescrição. Rev. abordagem Gestalt, Goiânia, v. 14, n. 1, p. 102-108, jan/jun. 2008.

ROSADO-NUNES, Maria José. Gênero e Religião. Estudos Feministas, Florianópolis, UFSC, v. 13, n. 2 , 2005.

SANTOS, Elder Cerqueira; KOLLER, Silvia Helena; PEREIRA, Maria Teresa Lisboa Nobre. Religião, Saúde e Cura: um Estudo entre Neopentecostais. Psicologia ciência e profissão, Brasília, v. 24, n. 3, p. 111-117, dez. 2004.

SARTI, Cynthia A. A família como ordem moral. Cadernos de Pesquisa, São Paulo, v.1, n. 91, p. 46-53, nov. 1994.

SCOTT, Joan W. Gênero: uma categoria útil de análise histórica. Revisão de Tomaz Tadeu da Silva. Tradução de Guacira Lopes Louro. Educação \& Realidade, Porto Alegre, v. 20, n. 2, p. 71-99, jul./dez. 1995.

THOMPSON, Frank Charles. Bíblia Thompson. Trad. João Ferreira de Almeida. São Paulo: Editora Vida, 2007.

Recebido em: 12/03/2017.

Aceito em: 21/05/2018.

\section{POLÊM!CA $\mid$ LABORE}

